\title{
Pemahaman Guru PJOK Tentang Standar Kompetensi Profesional
}

Septian Raibowo ${ }^{1}$, Yahya Eko Nopiyanto ${ }^{2}$, Muhammad Khairul Muna ${ }^{3}$. Pendidikan Jasmani, Universitas Bengkulu ${ }^{\mathbf{1 , 2}}$,

Pascasarjana Pendidikan Olahraga, Universitas Negeri Malang ${ }^{3}$

Email : septianraibowo@unib.ac.id ${ }^{1}$, yahyaekonopiyanto@unib.ac.id ${ }^{2}$,khairulmuna123@gmail.com³

\section{Abstrak}

Proses belajar terjadi karena adanya interaksi antara seseorang dengan lingkungannya Proses tersebut Disekolah tidak hanya belajar tapi yang paling terpenting adalah pendidikan. Karna pendidikan yang akan membentuk watak seseorang pengetahuan akan memperlancar prosesnya Salah satu pembelajaran dan pendidikan karakter di Sekolah adalah pendidikan jasmani. Pendidikan Jasmani adalah aktivitas psikomotoriak yang dilaksanakan atas dasar pengetahuan (kognitif), dan pada saat melaksanakannya akan terjadi perilaku pribadi yang baik (afektif). Untuk mencapai semua itu dibutuhkan guru yang berkompetensi. Salah satu kompetensinya adalah kompetensi profesional. Penelitian ini menggunakan pendekatan penelitian kualitatif. Sumber data utama dalam penelitian kualitatif ialah kata-kata, dan tindakan, selebihnya adalah data tambahan seperti dokumen dan lain-lain. Teknik pengumpulan data terdiri atas (1) Observasi, (2) wawancara/Interview, (3) Dokumentasi. Teknik analisis data kualitatif dalam penelitian ini menggunakan model Miles dan Huberman yaitu dengan kegiatan data reduction, data display, dan conclusion drawing/ verification. Hasil penelitian menunjukan bahwa pemahaman guru PJOK tentang kompetensi profesional sangat beragam, diantaranya (1) Guru harus menguasai materi, membuat inovasi dalam pembelajaran dan memaksimalkan sarana dan prasarana untuk menunjang pembelajaran, (2) Guru harus menghindari prilaku tindakan indisipliner, seperti datang tepat waktu, mengutamakan kepentingan tugas yang sudah dibebankan diatas kepentingan pribadi, (3) Guru harus "melek" teknologi dan memanfaatkannya sebagai media pembelajaran.

Kata Kunci: Guru PJOK, Standar Kompetensi Guru, Kompetensi Profesional.

\section{PJOK Teachers' Understanding of Professional Competency Standards}

\section{Abstract}

The learning process occurs because of the interaction between a person and his environment. The process is not only learning but also the most important thing is education. Education will shape a person's character. One of the character education in schools is physical education. Physical Education is a psychomotor activity that is carried out on the basis of knowledge (cognitive), and at the time of implementing it will occur good personal behavior (affective). To achieve all of that, competent teachers are needed. One of the competencies is professional competence. This research uses a qualitative research approach. The main data sources in qualitative research are words, and actions, the rest are additional data such as documents and others. Data were collected using (1) observation, (2) interview (3) documentation. Qualitative data analyzed using the Miles and Huberman model, namely data reduction, data display, and conclusion/ verification activities. The results showed that PJOK teachers' understanding of professional competence was very diverse, including (1) Teachers must take control the material, make innovations in learning and maximize facilities and infrastructure to support learning, (2) Teachers must avoid disciplinary action behaviors, such as arriving on time, give priority to the interests of tasks that have been charged above personal interests, (3) Teachers must "literate" technology and use it as a learning media.

Keywords: PJOK Teachers, Teacher Competency Standards, Professional Competence. 


\section{PENDAHULUAN}

Belajar adalah suatu proses yang kompleks yang terjadi pada diri setiap orang sepanjang hidupnya, baik di formal maupun non formal. Kebanyakan orang menilai belajar hanya pada sekolah akan tetapi pengalaman hasil mendengar dan melihat juga dinamakan belajar. Menurut Pereira, at all (2016:569-577) belajar adalah proses penemuan dipandu dengan tugastugas yang diselenggarakan untuk memberlakukan kerja, pemecahan masalah, refleksi kritis dan berinteraksi. Bagi anak usia sekolah belajar adalah suatu proses menuju pengetahuan. Proses belajar akan terjadi karena adanya interaksi antara seorang guru dengan lingkungannya. Oleh karena itu, belajar dapat terjadi kapan saja dan dimana saja. Salah satu pertanda bahwa seseorang itu sendiri telah menjalani pembelajaran adalah dengan adannya perubahan tingkah laku pada diri orang itu yang mungkin akan disebabkan oleh terjadinya perubahan pada tingkat pengetahuan, keterampilan, atau sikap. Proses pembelajaran yang dilaksanakan secara formal disekolah, tidak lain bertujuan untuk mengarahkan perubahan pada diri pebelajar secara terencana, baik dalam aspek kognitif, afektif maupun psikomotorik (Arsyad, 2013).

Pembelajaran di sekolah tidak hanya dilakukan di kelas saja, akan tetapi juga di lapangan seperti halnya praktik dalam pelajaran pendidikan jasmani. Awalnya pendidikan jasmani dicanangkan oleh pemerintah melalui kementrian pendidikan dan pengajaran bertugas menyelenggarakan latihan-latihan jasmani dikalangan pemuda untuk memperoleh kondisi badan yang baik guna memasuki angkatan perang (Roesdiyanto \& Sudjana 2009:116). Pendidikan jasmani merupakan sekumpulan aktivitas psikomotorik yang dilaksanakan atas dasar pengetahuan (kognitif), dan pada saat pelaksanaanya akan terjadi perubahan perilaku pribadi yang terkait dengan sikap/afektif (seperti kedisiplinan, kejujuran, percaya diri, sportivitas) serta perilaku sosial (seperti kerjasama, dan peduli sesama) (Widijoto,2006)

Seorang guru mempunyai peran yang sangat strategis dalam upaya mewujudkan tujuan pembangunan nasional khususnya dibidang pendidikan dan pengajaran, sehingga perlu dikembangkan sebagaimana tenaga profesi yang bermartabat dan berasaskan professional lainnya. Kualitas seorang guru tergantung dari kompetensinya. Kompetensi yang harus dimiliki guru menurut undang undang nomor 14 tahun 2005 tentang guru dan dosen pasal 10 meliputi "kompetensi pedagogik, kompetensi professional, kompetensi kepribadian, dan kompetensi sosial. Kompetensi profesional adalah tingkat kecakapan guru dalam menguasai materi ajar secara luas dan mendalam, mencakup penguasaan kurikulum, bahan ajar mata pelajaran di sekolah dan substansi keilmuan yang menaungi materinya, serta penguasaan terhadap struktur dan metodologi keilmuannya. (Saefuddin, 2015).

\section{METODE}

Metode penelitian yang digunakan adalah pendekatan penelitian kualitatif. Penelitian kualitatif merupakan penelitian yang bertujuan untuk melihat kondisi atau keadaan objek yang alamiah dengan peneliti sebagai instrumen pengumpul data, dan juga pendekatan penelitian yang menekankan pada hasil pengamatan dan wawancara oleh peneliti, Dengan menggunakan pendekatan ini, agar dapat memperoleh data yang mendalam dan bermakna langsung dari sudut padang subjek pembelajaran utama yaitu fokus utama dalam penggalian informasi ini adalah mengungkapkan pemahaman guru PJOK tentang standar kompetensi guru yaitu kompetensi profesional.

Lokasi pelaksanaan pengumpulan data adalah beberapa Sekolah Menengah Pertama (SMP) Negeri di Kecamatan Sungai Raya Kabupaten Kuburaya. Subjek penelitian adalah para guru pendidikan jasmnai olahraga \& kesehatan 
(PJOK) dengan kriteria yaitu (1) kualifikasi sarjana (S1) dan linier dalam bidang keilmuannya, (2) berstatus sebagai Pegawai Negeri Sipil (PNS) dan Honorer/GTT, (3) minimal memiliki pengalaman mengajar selama satu semester atau lebih. Hal ini dilakukan untuk menjaring informasi yang berkualitas, dengan asumsi guru-guru dengan karakteristik tersebut memiliki pengetahuan, wawasan dan pemahaman sebagai informan dalam pengumpulan informasi tersebut.

Sumber data dalam penelitian ini terdiri dari 2 (dua), yaitu data primer dan data sekunder. Data primer adalah data yang diperoleh langung melalui metode pengamatan dan wawancara dengan responden. Dalam hal ini sumber data utama adalah guru PJOK yang memiliki kriteria sesuai dengan subjek penelitian. Teknik wawancara yang digunakan dalam rangka mengumpulkan informasi dari data primer ini adalah teknik wawancara tak berstruktur, yang berpedoman hanya memuat garis-garis besar yang akan ditanyakan. Data sekunder adalah data tambahan berupa informasi dan bersifat melengkapi data primer. Data tersebut berupa dokumen/arsip seperti perangkat pembelajaran, dokumentasi pendukung yang sudah ada maupun yang dihasilkan sendiri yang mendukung tentang tercapainya pemahaman kompetensi profesional guru PJOK.

Prosedur pengumpulan data menggunakan metode observasi atau pengamatan secara langsung, dan metode wawancara, serta dokumentasi.

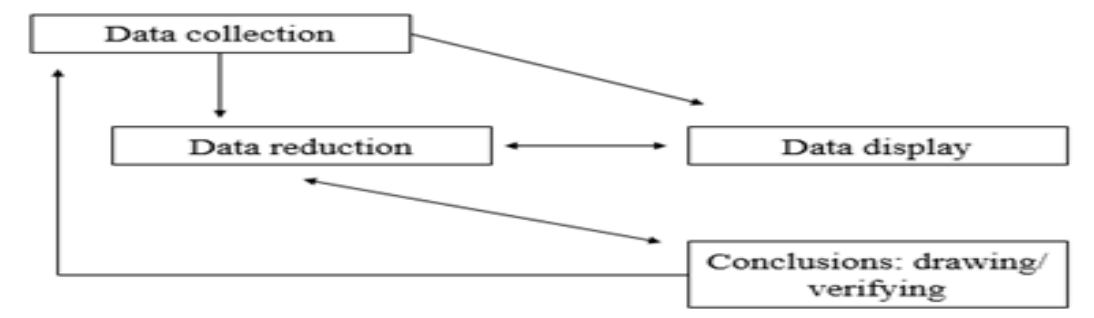

Gambar 1. Interactive Model (Sumber: Sugiyono, 2012:247)

Teknik analisis data yang digunakan menggunakan teknik analisis data kualitatif dengan model Miles dan Huberman yaitu dengan kegiatan data reduction, data display, dan conclusion drawing/verification.

Berikut penjelasan dari interactive model tersebut:

1. Pengumpulan data (Data collection) dilakukan dengan jalan observasi, wawancara, dan dokumentasi. Data-data dari lapangan itu kemudian dicatat dalam catatan lapangan berbentuk deskriptif tentang apa yang dilihat, apa yang didengar, dan apa yang dialami atau dirasakan oleli subjek penelitian. Catatan deskriptif adalah catatan data alami, apa adanya dari lapangan tanpa adanya komentar atau tafsiran peneliti tentang fenomena yang dijumpai. Dari catatan lapangan peneliti perlu membuat catatan reflektif. Catatan reflektif merupakan catatan dari peneliti sendiri yang berisi komentar, kesan, pendapat, dan penafsiran terhadap fenomena yang ditentukan berdasarkan fokus penelitian tentang kompetensi profesional guru PJOK.

2. Reduksi data (data reduction). Data diperoleh dari lapangan yang jumlahnya cukup banyak sehingga perlu dicatat secara teliti dan rinci. Reduksi data dilakukan dengan membuat rangkuman data yang diperoleh dari hasil wawancara, observasi dan analisis dokumen administrasi dan perangkat pembeljaran guru. Kemudian dilakukan pemilihan dan pengelompokan hal-hal yang pokok 
kemudian dicari tema dan pola yang sesuai dengan fokus penelitian.

3. Penyajian data (data display). Penyajian data yang dilakukan dalam penelitian kualitatif adalah berbentuk teks naratif dari data catatan lapangan. Penyajian data merupakan tahapan untuk memahami apa yang sedang terjadi dan apa yang harus dilakukan. Selanjutnya untuk dianalisis dan diambil tindakan yang dianggap perlu. Penyajian data dilakukan dengan menyampaikan data hasil reduksi kedalam bentuk tabel atau grafik untuk mempermudah dalam memahami karena lebih terorganisir dan tersusun dengan pola hubungan.

4. Membuat kesimpulan (conclusion drawing). Kegitan ini merupakan penarikan kesimpulan dan memverifikasi temuan data dengan teori yang digunakan dalam penelitian. Dalam hal ini dilakukan dengan cara mendiskripsikan data hadil temuan penelitian dalam pembahasan. Pembahasan dilakukan pada data temuan penelitian dengan teori-teori yang digunakan sebagai landasan penelitian.

Penelitian kualitatif harus mengungkap kebenaran yang objektif. Karena itu keabsahan data dalam sebuah penelitian kualitatif sangat penting. Melalui keabsahan data kredibilitas (kepercayaan) penelitian kualitatif dapat tercapai. Dalam penelitian ini untuk mendapatkan keabsahan data dilakukan dengan triangulasi. Adapun triangulasi adalah teknik pemeriksaan keabsahan data yang memanfaatkan sesuatu yang lain di luar data itu untuk keperluan pengecekan atau sebagai pembanding terhadap data itu (Moleong, 2007:330). Dalam memenuhi keabsahan data penelitian ini dilakukan triangulasi dengan penguatan dari berbagai sumber. Triangulasi dengan sumber berarti membandingkan dan mengecek di sumber yang berbeda untuk mendapatkan kepercayaan suatu informasi yang diperoleh melalui waktu dan alat yang berbeda dalam penelitian kualitatif. Pengecekan keabsahan data dalam penelitian ini dilakukan dalam upaya memperoleh kredibilitas hasil penelitian. Dengan menggunakan Triangulasi data, dengan sumber yang dilaksanakan pada penelitian ini yaitu membandingkan hasil wawancara dengan isi dokumen yang berkaitan dalam penelitian. Sehingga data yang peneliti didapat dari subjek yang diwawancarai bisa dipertanggung jawabkan.

\section{HASIL DAN PEMBAHASAN Hasil}

Menjadi seorang tenaga pendidik atau yang kita kenal dengan nama "guru", haruslah memahami tugas-tugas dan kewajiban dalam melaksanakan tugas sebagai seorang guru. Hal tersebut sudah diatur dalam undang-undang yang didalamnya adalah standar kompetensi guru. Standar kompetensi guru dibagi menjadi 4 yaitu kompetensi sosial, kompetensi kepribadian, kompetensi pedagogik, dan kompetensi profesional.

Kompetensi profesional menjadi fokus utama yang sangat penting untuk diketahui, dipahami dan dilaksanakan oleh seorang guru. Dari hasil pengumpulan informasi tentang pemahaman guru PJOK tentang standar kompetensi guru yaitu kompetensi profesional didapatkan data berupa: (1) guru mengartikan kompetensi profesional yaitu harus menguasai materi yang disampaikan dan membuat inovasi dalam pembelajaran serta memaksimalkan sarana dan prasarana untuk menunjan pembelajaran; (2) guru harus menghindari perilaku tindakan indisipliner, seperti datang tepat waktu dan mengutamakan kepentingan tugas yang telah dibebankan diatas kepentingan pribadi; (3) guru harus "melek" teknologi dan memanfaatkannya sebagai media pembelajaran.

\section{Pembahasan}

Memahami materi yang akan diajarkan merupakan strategi utama dalam proses belajar mengajar (Berlian, 2013). Pemhahaman guru tersebut mencerminkan bahwa guru harus menguasai materi yang diajarkan agar pembelajaran dapat terprogram dengan baik, sesuai dengan standar pendidikan nasional dan tujuan pendidikan yang diinginkan bisa tercapai.

Pemahaman tentang tindakan displin adalah salah 
satu yang harus dipahami oleh seorang guru untuk bisa masuk kedalam kriteria guru dengan kompetensi profesional. Pada dasarnya peserta didik senang denga diterapkan disiplin dikelas, tetapi dengan konsekuensi guru juga harus bersikap disiplin (Mulyana, 2010:29). Dengan penerapan sikap disiplin, baik guru maupun siswa akan terciptanya suasana kelas yang kondusif di setiap pelajarannya. Kelas yang kondusif mencerminkan suasana kelas menjadi lebih teratur dalam manajemen kegiatan dan waktu. Dengan kata lain guru yang profesional adalah guru yang mampu menerapkan sikap disiplin dan mampu mengelola antara kegiatan dan waktu.

Penguasaan media pembelajaran pada masa sekarang terkait dengan inovasi dalam mengajar. Hal tersebut akan menjadikan kelas yang kondusif dan menyenangkan serta siswa akan lebih tertarik dan lebih semangat dalam mengikuti kegiatan belajar mengajar. Dengan perkembangan teknologi dan informasi yang sangat pesat, pada saat ini pengguasaan media sangat diperlukan karena pembelajara masa depan akan mengubaha pendekatan pembelajaran tradisional kearah pembelajaran masa depan (visioner) yang disebut sebagai pembelajaran abad pengetahuan (Dwiyogo, 2016).

Inovasi dalam mengajar bukan hanya fokus dengan membuat siswa tertarik dengan pembelajaran, melainkan inovasi dalam memodifikasi sarana dan prasarana untuk menanggulangi kekurangan dalam proses pencapaian tujuan pembelajaran itu sendiri. Nacar E (2013:627:631) sekolah wajib menyediakan fasilitas olahraga yang layak dan aman bagi siswa agar tercapainya pengetahuan yang diberikan terserap secara maksimal. Berbicara sarana dan prasarana, sudah menjadi rahasia umum bahwasanya sarana dan prasarana yang ada disekolah antara sekolah yang ada di perkotaan dengan di pedesaan sangat jauh berbeda, hal itu disebabkan oleh beberapa faktor, antara lain lingkungan, ekonomi dan sebagainya. Untuk itu guru yang dapat mengatasi kekurangan sarana dan prasarana tersebut dengan cara inovasi memodifikasinya adalah guru yang profesional

\section{SIMPULAN}

Pemahaman tentang kompetensi profesional didapatkan hasil yang sangat beragam. Keberagaman dalam pemahaman tentang kompetensi profesional guru PJOK terjadi karena perbedaan konsep yang diterima. Diantaranya adalah ada yang memahami konsep kompetensi profesional sesuai dengan peraturan pemerintah No 16 Tahun 2007 dan juga beberapa menjelaskan pemahaman kompetensi profesional dengan pemahaman sendiri. Hal tersebut terjadi karena guru kurang memahami dan kurang membaca tentang kompetensi profesional seorang guru khususnya tentang pendidikan jasmani. Saran yang bisa disampaikan adalalah, terhadap guru adalah selalu up to date dengan perkembangan yang ada, dan tidak menutup diri. Untuk para pemangku kebijakan (stakeholder) yang terkait, harus lebih gencar melakukan sosialisai tentang implementasi Undang-undang No 15 Tahun 2005 tentang guru dan dosen.

\section{DAFTAR PUSTAKA}

Arsyad, A. (2003). Media Pembelajaran. Jakarta: PT. Raja Grafindo Persada.

Berlian, I. (2013). Begitu Pentingkah Strategi Belajar Mengajar Bagi Guru? Jurnal Forum Sosial, 6(1), 241-256.

Dwiyogo, D,W. (2016). Pembelajaran Visioner. Jakarta : Bumi Aksara.

Mulyana A,Z. (2010). Rahasia Menjadi Guru Hebat. Surabaya: CV. Grasindo.

Nacar E, Gacar A, Fatih K, Camel G. (2013). Analysis for Sports Facilities in Sports High School in terms of Quality and Quantity. Australian Journal of Basic and Applied Sciences, 7(2). 627-631.

Pereira, J. at all. (2016). Sport Education and Direct Instruction Units: Comparison of Student Knowledge Development in Athletics. Journal of sport science dan medicine 15(-), 569-577.

Roesdiyanto \& Sudjana. (2009). Sejarah Olahraga 
dan Pendidikan Jasmani. Malang : UM Press.

Saefuddin, U. 2015. Hakikat Kompetensi Guru. mengembangkan kompetensi melalui kegiatan pengembangan diri di KKG. diakses tanggal 1 maret 2019.

Sugiyono. (2012). Metode Penelitian Kuantitatif Kualitatif dan R\&D. Bandung: Rosdakarya.

Undang-undang Republik Indonesia Nomor 14 Tahun 2005 tentang Guru dan Dosen. 2010. Jakarta:

Widijoto, H. (2006). Buku Petunjuk Teknis Praktik Pengalaman Lapangan. Malang: Universitas Negeri Malang UPT Program Pengalaman Lapangan. 